\title{
ÇOK AMAÇLI ÜRETIM SÜREÇLERINIIN BULANIK KARAR ORTAMINDA İNCELENMESİ: BULANIK HEDEF PROGRAMLAMA VE BİR UYGULAMA
}

Nurullah UMARUSMAN ${ }^{1}$

ÖZ
Received Date (Başvuru Tarihi): 24/05/2018

Accepted Date (Kabul Tarihi): 19/07/2018

Published Date (Yayın Tarihi): 02/09/2018

Hedef Programlamada karar verici tarafindan belirlenen hedeflerin arzu edilen seviyeleri ĕger gerçekçi değil ise, çözümün sonucunda hedeflerden sapmalar çok yüksek değerde gerçekleşebilir. Bu durum karar vericinin yanlış karar almasına yol açar. Benzer durum Bulanık Hedef programlama için de geçerlidir. Çünkü bulanık hedefler ve bu hedeflerin tolerans değerleri doğru belirlenmezse hedeflerden sapmalar artacaktır. Ayrıca ister Hedef Programlama problemi ister Bulanı Hedef programlama probleminde ĕger hedeflerin yanı sira kisit fonksiyonları da olursa, kısıtlara bağlı çözüm gerçekleşeceği için doğru tanımlanmamış hedef değerlerden sapmalar çok fazla olacaktır. Çünkü hedefler kısıtlar tarafindan sınırlandırılır. Bu çalışmada Çok Amaçlı Doğrusal Programlama modelinde kurulan el yapımı mobilya üretimi yapan bir işletme problemi Bulanık Hedef Programlama modelinde çözülebilmesi için ilk olarak amaç fonksiyonlarının pozitif ve negatif ideal çözümleri belirlenmiştir. Daha sonra her bir amaç fonksiyonu pozitif ve negatif ideal çözümler kullanılarak bulanık hedeflere dönüştürülmüştür.

Anahtar Kelimeler: Bulanık Hedef Programlama, İdeal Çözümler, MA Yaklaşımı

JEL Kodları: C61, M11

\section{EVALUATION OF PRODUCTION PROCESSES IN FUZZY DECISION ENVIRONMENTS: FUZZY GOAL PROGRAMMING AND AN APPLICATION}

\begin{abstract}
If the aspiration levels of the goals are set unrealistically by the decision maker in Goal Programming, the deviations from the goals could occur too high as a result of the solution. It leads the decision maker to make incorrect decisions. It is also the case for Fuzzy Goal Programming. When the fuzzy goals and their tolerance levels are not defined properly, there will be deviations from the goals. Additionally, if there are constraint functions besides the goals in the problems of either Goal Programming or Fuzzy Goal Programming, the solutions will deviate greatly from the incorrectly defined goal values as the solutions are realized based on the constraints. It is because the goals are limited by the constraints. This study firstly defines the positive and negative ideal solutions of objective functions in the problem organized in Multiobjective Linear Programming model for a business which manufactures hand crafted furniture. Afterwards, each objective is transformed into fuzzy goals using positive and negative ideal solutions.
\end{abstract}

Keywords: Fuzzy Goal Programming, Ideal Solution, MA Approach

JEL Codes: C61, M11

\footnotetext{
${ }^{1}$ Dr. Öğrt. Üyesi, Aksaray Üniversitesi, nurullah.umarusman@aksaray.edu.tr
} 


\section{GİRIŞ}

Hedef Programlamanın felsefi temelini Simon(1960)'ın “amaçların tatmini” kavramı oluşturur. $\mathrm{Bu}$ kavrama göre günümüz karmaşık organizasyonlarında karar vericiler iyi tanımlanmış fayda fonksiyonunu maksimize etmeye çalışmazlar. Çünkü çatışan çıkarlar ve bilgi yetersizliği sebebiyle karar vericilerin tercihlerini güvenilir bir matematiksel modele aktarmaları neredeyse mümkün değildir. Bu sebeple karar vermenin bu türünde karar verici hedeflerini en yüksek değerde gerçekleştirmeye çalışır (Jones ve Tamiz, 2010). Bu sebeple Hedef Programlama yönteminde elde edilen sonuçlar optimal çözüm yerine tatminkar çözüm olarak isimlendirilir (Min ve Storbeck, 1991). Çok Amaçlı Karar Verme yöntemleri sınıflandırması içerisinde yer alan Hedef Programlama, tercih bilgilerinin “öncelikli kullanıldığı yöntemler” içerisinde karar vericiden sağlanan bilgiler doğrultusunda hedefler arasındaki öncelik sıralaması ve/veya göreceli önem düzeylerine göre çözüm yapabilmektedir. Hedef Programlama üzerine ilk çalışma Charnes, Cooper ve Ferguson (1955) tarafından "sınırlandırılmış regresyon" tahmincilerini belirlemek için başlatılmış olmasına karşın Hedef Programlama kavramı Charnes ve Cooper (1961) tarafından ilk kez kullanılmış ve formülasyonu yapılmıştır. Doğrusal Programlanın da özel bir uzantısı olarak kabul edilen Hedef Programlamanın temele amacı hedeflerden sapmayı minimum kılmaktır ( Lee ve Moore 1975; 199). Matematiksel olarak Hedef Programlama yaklaşımı aşağıdaki gibidir:

$$
\text { Minimize } Z=\sum_{i=1}^{m}\left(p_{i}+n_{i}\right)
$$

Kisitlar;

$$
\begin{aligned}
& f_{i}(x)+n_{i}-p_{i}=b_{i} \\
& x \in F \\
& n_{i}, p_{i} \geq 0 \\
& i=1,2, \ldots, m .
\end{aligned}
$$

Burada;
$f_{i}(x): i$-inci hedef fonksiyonu,
$p_{i}: i$-inci hedefin pozitif sapmas1,
$n_{i}: i$-inci hedefin negatif sapmas1,
$F$ :uygun çözün bölgesidir. 
Hedef Programlama yaklaşımı tatminkâr çözümü belirlemek için karar vericinin birden fazla hedefini aynı anda ele alması önemlidir. Ayrıca, hedefler hakkında kısmi bilgiye sahip olunması sebebiyle her hedefin arzu edilen değerinin kesin olarak hesaplanması karar verici için zordur (Zeleny,1982). Hedef Programlamada minimizasyon süreci üç farklı yaklaşımla gerçekleştirilir:

- Ağırlıklı Hedef Programlama üzerine ilk çalışma Ijiri (1965) tarafından öncelik ve ağırlık faktörlerinin bir arada düşünüldüğü modelle başlamıştır. Daha sonra Charnes ve Cooper (1977) yalnızca ağırlık faktörlerini içeren Ağırlıklı Hedef Programlama modelini önermiştir. Ağırlıklı Hedef Programlama bütün hedefler aynı anda göz önünde bulundurarak, hedefler ve hedeflere ait arzu edilen seviyeler arasındaki ağırlıklandırılmış sapmaların toplamı minimize yapar.

- Charnes ve Cooper (1977), İjiri (1965) tarafından önerilen modelden ağırlık faktörlerini çıkararak her bir hedef için öncelik sıralamasının olduğu Öncelikli Hedef Programlama modelini önermiştir. Bu modelde hedeflerin öncelik sıralaması korunarak, hedeflerden öncelikli sapmalar minimize yapılır.

- $\quad$ Flavell (1976) tarafından geliştirilen Minmaks Hedef Programlama modeli ise ağırlıklı ve öncelikli yapılardan farklı olarak sapan değişkenlerin toplamlarının minimizasyonu yerine maksimum sapmanın minimizasyonu araştırır.

Geliştirilen bu yaklaşımların yanı sıra Romero (1991), Schniederjans (1994), Jones ve Tamiz (2010) tarafından yazılan bilimsel kitaplar Hedef Programlamanın teorik gelişiminde ve gerçek dünya problemlerine uygulanabilirliği açısından çok önemli katkı sağlamıştır. Bu çalışmada, Çok Amaçlı Doğrusal Programlama probleminin çözümünün Bulanık Hedef Programlamaya göre yapılabilmesi için pozitif ve negatif ideal çözüm kavramları kullanılarak, amaç fonksiyonlarının bulanık hedef fonksiyonlarına dönüşümü bulanık üyelik fonksiyonları tanımlanarak gerçekleştirilmiştir. Daha sonra Mohammed Ali Yaghoobi ve Mehrdad Tamiz (2007) tarafindan geliştirilen MA yaklaşımına göre Bulanık Hedef Programlama modeli oluşturulmuştur. Bu çalışmanın temel amacı birden fazla, birbiriyle çatışan ve ihtilaflı amaçlara sahip bir üretim probleminin bulanık karar ortamında nasıl çözülebileceğini araştırmaktır. Bu araştırmanın Bulanık Hedef Programlama literatüründeki çalışmalardan en belirgin farkl, bulanık hedeflerin karar vericiden sağlanan bilgilere göre oluşturulmasının yerine pozitif ve negatif ideal çözümler kullanılarak amaçların bulanık hedeflere dönüş̧ı̈rülmesidir. 


\section{LITERAÜR İNCELEMESI}

Zadeh (1965) tarafından geliştirilen "Fuzzy Sets" teorisi bilim dünyasında bir ufuk açmış ve daha sonra Bellman ve Zadeh (1970) tarafindan önerilen Bulanık Ortamda Karar Verme süreci ile birlikte Matematiksel Programlama yöntemlerinde olduğu gibi Hedef Programlama yöntemlerinde de birçok yaklaşım geliştirilmiştir. $\mathrm{Bu}$ başlık altında Bulanık Hedef Programlamanın teorik gelişim süreci ve üretim problemleri için literatür araştırması sunulmuştur. Bulanık Hedef Programlamanın teorik gelişim sürecindeki temel bilimsel makalelerden oluşan literatür şu şekilde verilebilir: Bulanık Hedef Programlamada ilk çalışma Narasimhan (1980) tarafından başlatılmış ve ilk kez bulanık ağırlıkları kullanmıştır. Hannan (1981) geliştirdiği modelde parçalı doğrusal üyelik fonksiyonunu kullanmıştır. Rubin ve Narasimhan (1984) hedefleri bulanık önceliklerini içeren yeni bir yaklaşım önermiştir. Yang vd. (1991) üçgensel doğrusal üyelik fonksiyonu kullanarak Bulanık Hedef Programlama problemlerinin çözümü için yeni bir model geliştirmiştir. Chen and Tsai (2001) bulanık hedeflerin başarım derecesini yükseltmek için geliştirdiği modelde farklı önem ve öncelikleri kullanmıştır. Lin (2004) Bulanık Hedef Programlama için yeni bir ağırlıklı maksmin modeli önermiştir. Yaghoobi ve Tamiz (2007) Minmaks Hedef Programlamayı temel alan ve simetrik olmayan üçgensel üyelik fonksiyonu kullanması sebebiyle Hannan (1981) yaklaşımının bir uzantısı olarak da kabul edilen MA-yaklaşımını önermiştir. Gupta and Bhattacharjee (2012) ağırlıklandırma yöntemini kullanarak bulanık hedef programlama problemlerinin çözümü için farklı iki yöntem geliştirmiştir. Cheng (2013) hedefler arasında hiyerarşiyi içeren Bulanık Hedef Programlama problemlerinin çözümü için hedeflerin hem öncelik sırası hem de bulanıklığını içeren bir yaklaşım sunmuştur. Literatürde Bulanık Hedef Programlama için geliştirilen birçok yöntem olmasına karşın, bu yaklaşımların Narasimhan (1980) ve Hannan (1981) tarafından önerilen yaklaşımların birer uzantısı oldukları görüşü yaygındır (Yaghoobi ve Tamiz 2007).

Bulanık Hedef Programlamanın bu yaklaşımları birçok işletme probleminin çözümünde kullanılmıştır. Üretim süreçlerinin ele alındığı bir literatür incelemesi de şu şekilde özetlenebilir. Liang (2007), üretim/ulaştırma planlama karar problemleri için toplam dağıtım ve üretim maliyetlerini, iade edilen ürünlerin toplamını ve her kaynaktaki mevcut kapasite, işgücü seviyesi ve kotaya bağlı olarak toplam teslimat süresini, talep öngörümü ile depo alanı kullanımını minimize etmek için Bulanık Hedef Programlamayı kullanmıştır. Tsai vd. (2008) Çelik endüstrisinde, net karları maksimize etmek, geç yükleme oranını en aza indirmek gibi hedeflerini üretimine bağlı olarak Bulanık Hedef Programlama problemini formüle etmiştir. 
Erpolat (2010) kanatlı hayvancılık sektöründe faaliyet gösteren bir firmanın üretim planlaması ele almış, kurulan model Bulanık Hedef Programlama ve Öncelikli Hedef Programlamaya göre çözüp karşılaştırmalı bir değerlendirme yapmıştır. Silva ve Marins (2014) Brezilya'da şeker ve etanol üretimi yapan bir firmanın, gelecek döneminin üretim planlaması için Bulanık Hedef Programlama kullanarak yöneticilere öneride bulunmuştur. Özkan ve Bircan (2016) İstanbul'da faaliyet gösteren bir deterjan üretim fabrikasının bazı ürünlerinin kalitesini arttırmak amacıyla üretim planlama problemi için Bulanık Hedef Programlama ve Ağırlıklı Hedef Programlama yaklaşımları kullanarak çözüm araştırmıştır. Lutero vd. (2016) Filipinlerde biodizel üretiminin kaynağı olan hindistancevizi, jatropha kullanarak üç farklı hedefe sahip Bulanık Hedef Programlama problemini formüle etmiştir. Mokhtaria ve Hasani (2017) bir işletmenin üretim tesislerinde daha temiz bir üretim-taşıma planlaması probleminin çözümü için Bulanık Hedef Programlamayı önermiş ve elde edilen sonuçlarda envanter ve fazla mesai üretim oranlarının azaldığı belirlenmiştir. Chen vd. (2017) müşteri memnuniyetini üst düzeye çıkarmak amacıyla yeni ürün planlaması için Kalite Fonksiyonu Göçerimi ve Bulanık Hedef Programlamayı kullanarak model önerisinde bulunmuştur.

Bu çalışmada Minmaks Hedef Programlama yöntemine bağlı Yaghoobi and Tamiz (2007) tarafından geliştirilen MA yaklaşımı kullanılmıştır. Bu yaklaşımla Aksaray'da mobilya sektöründe faaliyet gösteren ve el yapımı mobilya üretimi yapan işletmenin üretim süreci ele alınmıştır.

\section{BULANIK HEDEF PROGRAMLAMA}

Hedef Programlamanın Bulanık Karar ortamında incelenmesi sonucunda üç farklı tipte bulanık hedef tanımlanabilir. Bu hedeflerde hedeflerin sol taraf parametreleri birer sabitken, sadece hedeflerin arzu edilen seviyeleri bulanık sayı olarak ele alınıp tolerans değere sahip esnek hedefler ortay çıkmaktadır. (Tiwari, Dharmar \&Rao, 1986). Bu hedefler

$$
\begin{aligned}
& \text { Bukank Hedef } A:(A X)_{i} \leq b_{i} \\
& \text { Bukank Hedef } B:(A X)_{i} \cong b_{i} \\
& \text { Bulank Hedef C: }(A X)_{i} \cong b_{i}
\end{aligned}
$$

Burada, $(A X)_{i}=\sum_{i=1}^{k} a_{i j} x_{j}, \mathrm{j}=1,2, \ldots, \mathrm{n},{ }^{{ }^{\prime}}{ }^{w} \mathrm{i}$-inci hedefin arzu edilen seviyeleri olan $b_{i}$ 'nin bulanık sayıdan oluştuğunu göstermektedir. Bulanık hedefler farklı bulanık sayılarla tanımlanabilmektedir. Bu çalışmada Zimmerman (1978)'ın doğrusal üyelik fonksiyonuna göre Narasimhan (1980) ve Hannan, (1981a) tarafından kullanılan artan, azalan ve üçgensel üyelik 
fonksiyonları aşağıda açıklanmıştır. Bulanık Hedef için azalan üyelik fonksiyonu grafik olarak Şekil 1'de gösterilmiştir.

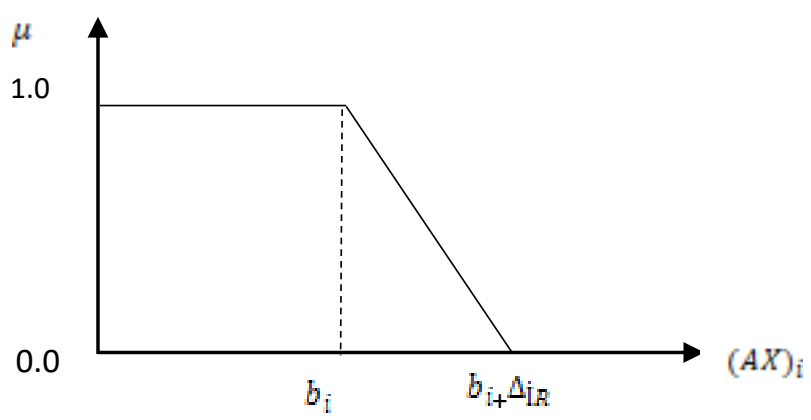

Şekil 1: Bulanık Hedef A için Üyelik Fonksiyonu

Şekil 1'de $\Delta_{\mathrm{i} R}$ hedefin arzu edilen seviyesi olan $b_{i}$ 'den sapma miktarıdır. Bu üyelik matematiksel olarak aşağıda verilmiştir.

$$
\mu_{i}(A X)=\left\{\begin{array}{ccc}
1 & (A X)_{i} \leq b_{i} \\
\frac{\left(b_{i}+\Delta_{\mathrm{i} R}\right)-(A X)_{i}}{\Delta_{\mathrm{i} R}}, & b_{i} \leq(A X)_{i} \leq b_{i}+\Delta_{\mathrm{I} R} \\
0 & , & (A X)_{i} \geq b_{i}+\Delta_{\mathrm{I} R}
\end{array}\right.
$$

Bulanık Hedef için artan üyelik fonksiyonu grafik olarak aşağıda gösterilmiştir.

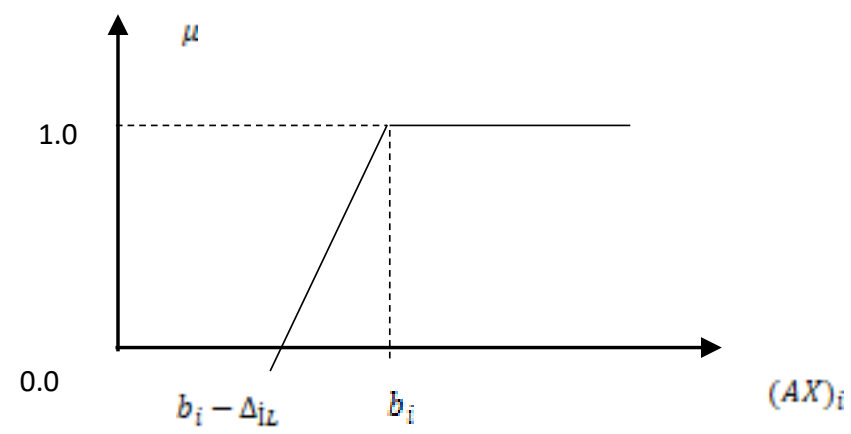

Şekil 2: Bulanık Hedef B için Üyelik Fonksiyonu

Artan üyelik fonksiyonu matematiksel olarak;

$$
\mu_{i}(A X)=\left\{\begin{array}{ccc}
1 & (A X)_{i} \geq b_{i} \\
\frac{(A X)_{i}-\left(b_{i}-\Delta_{\mathrm{i} L}\right)}{\Delta_{\mathrm{i} L}} & , & b_{i}-\Delta_{\mathrm{iL}} \leq(A X)_{i} \leq b_{i} \\
0 & , & (A X)_{i} \leq b_{i}-\Delta_{\mathrm{iL}}
\end{array}\right.
$$

yazılır. Burada $\Delta_{\mathrm{I} L}, b_{i}$ 'den sapma miktarını gösterir. Şekil 3’te Bulanık Hedef C için üçgensel üyelik fonksiyonu gösterilmiştir. $\Delta_{\mathrm{I} R}$ ve $\Delta_{\mathrm{i} L}, b_{i}$ 'den sapma miktarlarını gösterir. 


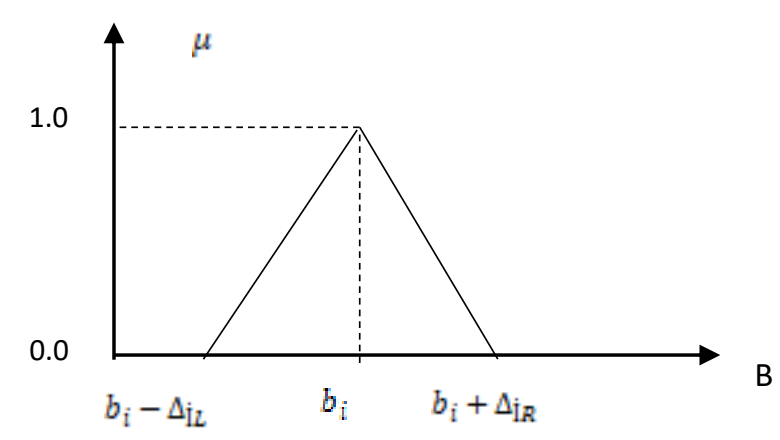

Şekil 3: Bulanık Hedef C için Üçgensel Üyelik Fonksiyonu

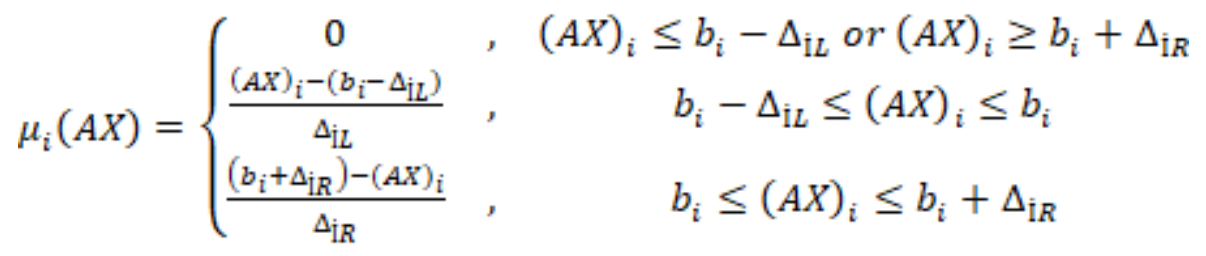

\subsection{MA Yaklașımı}

MA yaklaşımı, ağırlıklı ve öncelikli yapılardan farklı olarak sapan değişkenlerin toplamlarının minimizasyonu yerine maksimum sapmanın minimizasyonu gerçekleştiren Minmaks Hedef Programlama tabanlıdır. Yaghoobi ve Tamiz (2007) tarafından önerilen MA yaklaşımı matematiksel olarak aşağıda verilmiştir.

$\operatorname{Max} \lambda$

Kisitlar;

$$
\begin{gathered}
(A X)_{i}-p_{i} \leq b_{i} \\
\lambda+\frac{1}{\Delta_{i R}} p_{i} \leq 1 \\
(A X)_{i}+n_{i} \geq b_{i} \\
\lambda+\frac{1}{\Delta_{i L}} n \leq 1 \\
(A X)_{i}+n_{i}-p_{i}=b_{i} \\
\lambda+\frac{1}{\Delta_{i L}} n_{i}+\frac{1}{\Delta_{i R}} p_{i} \leq 1 \\
X \in C_{\sigma} \\
\lambda, p_{i}, n_{i} \geq 0 \text { ve } \lambda \in[0 ; 1]
\end{gathered}
$$


$(A X)_{i}:$ i-inci hedef,

$b_{i}$ : i-inci hedefin arzu edilen seviye değeri,

$n_{i}$ : i-inci hedefin negatif sapmas1,

$p_{i}:$ i-inci hedefin pozitif sapmas1,

$\Delta_{i R}:$ i-inci hedef azalan üyelik için tolerans değeri,

$\Delta_{i L}:$ i-inci hedef artan üyelik için tolerans değeri.

Eğer hedef tipi " $\leq$ " ise üyelik fonksiyonu (5), hedef tipi " $\geq$ "ise üyelik fonksiyonu (6) ve hedef tipi " =" ise üyelik fonksiyonu (7) kullanılır. MA yaklaşımında hedeflerin arasında öncelik sıralaması yerine eşit göreceli ağırlık faktörleri kullanılır. $\left((A X)_{i}-p_{i} \leq b_{i}\right)$ tipindeki hedef için negatif sapma istenen sapma olup pozitif sapma $p_{i}$ istenmeyen sapmadır ve bu sapma minimum yapılmak istenir. Diğer yandan bu hedefle ilgili olan $\left(\lambda+\frac{1}{\Delta_{i R}} p_{i} \leq 1\right)$ kısıtı da tolerans değerli $\left(\frac{1}{\Delta_{i R}} p_{i}\right)$ normalleştirilmiş oranını minimum kılarak $\lambda$ üyelik derecesini 1'e yaklaştırarak maksimum yapmaya çalışmaktadır. Benzer yorumlar diğer hedef tipleri için de yap1labilir.

\subsection{MA Yaklaşımı için İdeal Çözümlerin Kullanılması}

Bu başlık altında Çok Amaçlı Doğrusal Programlama açısından MA yaklaşımı yeniden düzenlenmiştir. Aşağıda verilen Çok Amaçlı Doğrusal Programlama problemi göz önünde bulundurulsun.

$$
\begin{aligned}
& \operatorname{Max} . Z_{k}=\left[Z_{1}, Z_{2}, \ldots Z_{l}\right]^{T}=\left[c_{1} x, c_{2} x, \ldots c_{l} x\right]^{T} \\
& \operatorname{Min} . W_{s}=\left[W_{1}, W_{2}, \ldots W_{r}\right]^{T}=\left[c_{1} x, c_{2} x, \ldots c_{l} x\right]^{T}
\end{aligned}
$$

Kisitlar;

$A x \leq b$,

$x \geq 0$,

Burada, $c_{k}, k=1,2, \ldots, l, c_{s^{\prime}} \mathrm{s}=1,2, \ldots r, x$ n-boyutlu vektör, $b m$-boyutlu vektör ve $A, m x n$ tipinde matris. Çok Amaçlı Doğrusal programlama problemlerinin çözümü sonucunda farklı isimlendirilen çözümler elde edilir. Bu çözümlerden en önemlileri pozitif ve negatif ideal 
çözümlerdir (Zeleny, 1982). Pozitif ideal çözümler her bir amaç fonksiyonunun verilen amaç yönünde çözümünden elde edilir.

$$
\mathrm{I}^{+}=\left[\mathrm{Z}_{1}^{+}, \mathrm{Z}_{2}^{+}, \ldots, \mathrm{Z}_{1}^{+}, \mathrm{W}_{1}^{+}, \mathrm{W}_{2}^{+}, \ldots, \mathrm{W}_{\mathrm{r}}^{+}\right]
$$

Pozitif ideal çözümler aynı zamanda her bir amaç fonksiyonunun en iyi performansını göstermektedir. Negatif ideal çözümler ise her bir amaç fonksiyonunun verilen amacın ters yönde çözümünden elde edilir.

$$
\mathrm{I}^{-}=\left[\mathrm{Z}_{1}^{-}, \mathrm{Z}_{2}^{-}, \ldots, \mathrm{Z}_{1}^{-} ; \mathrm{W}_{1}^{-}, \mathrm{W}_{2}^{-}, \ldots, \mathrm{W}_{\mathrm{r}}^{-}\right]
$$

Negatif ideal çözümler aynı zamanda her bir amaç fonksiyonunun en kötü performansı olarak isimlendirilir. MA yaklaşımı (8) için pozitif ve negatif ideal çözümlere bağlı olarak düzenleme aşağıda yapılmıştır. Bu düzenlemede "=" tipindeki hedefler kullanılmamıştır.

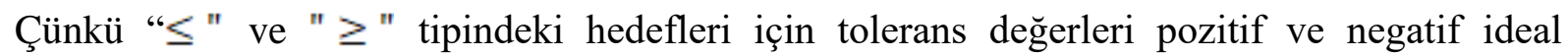
çözümlere göre belirlenebilir. "=” tipindeki hedef için ise karar vericiler tolerans değerlerini tanımlayabilirler. Buna göre pozitif ve negatif ideal çözümler açısından (8) ve (9)'a göre MA yaklaşımı;

\section{$\operatorname{Max} \lambda$}

Kisitlar;

$$
\begin{aligned}
& W_{s}(x)-p_{s} \leq \mathrm{W}_{s}^{+} \\
& \lambda+\frac{1}{\Delta_{i R}} p_{s} \leq 1 \\
& Z_{k}(x)+n_{k} \geq \mathrm{Z}_{1}^{+} \\
& \lambda+\frac{1}{\Delta_{i L}} n_{k} \leq 1 \\
& X \in C_{s}
\end{aligned}
$$

$\lambda, p_{i}, n_{i} \geq 0, \lambda \in[0 ; 1], k=1,2, \ldots, l$ ve $\mathrm{s}=1,2, \ldots, \mathrm{r}$

elde edilir. 
Burada;

$Z_{k}(x)$ : k-inci maksimizasyon yönlü amaç fonksiyonu

$\mathrm{Z}_{\mathrm{k}}^{+}: \mathrm{k}-1 \mathrm{ncı}$ amaç fonksiyonunun arzu edilen seviyesini gösteren pozitif ideal çözüm,

$\mathrm{Z}_{1}^{-}$: k-1ncı amaç fonksiyonunun negatif ideal çözüm değeri,

$n_{k}$ : k-inci amaç fonksiyonundan minimize yapılmak istenen sapma miktarı

$W_{s}(x)$ : s-inci minimizasyon yönlü amaç fonksiyonu,

$\mathrm{W}_{\mathrm{s}}^{+}$: s-inci amaç fonksiyonunun arzu edilen seviyesini gösteren pozitif ideal çözüm,

$W_{1}^{-}$: s-1ncı amaç fonksiyonunun negatif ideal çözüm değeri,

$p_{s}:$ s-inci amaç fonksiyonundan minimize yapılmak istenen sapma miktarı,

$\Delta_{i R}:$ i-inci hedef azalan üyelik için tolerans değeri $\left(\Delta_{i R}=\mathrm{W}_{\mathrm{r}}^{-}-\mathrm{W}_{\mathrm{r}}^{+}\right)$,

$\Delta_{i L}:$ i-inci hedef artan üyelik için tolerans değeri $\left(\Delta_{i L}=\mathrm{Z}_{1}^{+}-\mathrm{Z}_{1}^{-}\right)$.

\section{UYGULAMA}

Aksaray'da el yapımı salon mobilyası üretimi yapan bir işletme, iki farklı şekilde bu üretimi gerçekleştirmektedir; Birinci olarak müşteri talebine göre ürünleri ayrı ayrı olarak üretebiliyor, ikinci olarak da salon grubu (gümüşlük, tekli koltuk 2 adet, ikili koltuk ve üçlü koltuk) olarak üretebilmektedir. İşletme yönetiminin temel malzemeleri aynı kalitede olup sadece müşteri talebine göre aynı fiyat ve kalitede farklı desenli kumaş ve astar seçeneği sunmaktadır. Üretim sürecinde kullanılan hammadde kaynaklarının kullanım miktarları ile bu kaynakların toplam miktarları Tablo 1'de verilmiştir.

Tablo 1: Hammadde Kullanım Miktarları

\begin{tabular}{llllll}
\hline Hammadde & $\begin{array}{l}\text { Gümüşlük } \\
\left(x_{1}\right)\end{array}$ & $\begin{array}{l}\text { Tekli Koltuk-2 } \\
x_{1}\end{array}$ & $\begin{array}{l}\text { İkili Koltuk } \\
\left(x_{3}\right)\end{array}$ & $\begin{array}{l}\text { Üçlü Koltuk } \\
\left(x_{4}\right)\end{array}$ & Toplam \\
\hline Ahşap $\left(m^{3}\right)$ & 4 & 7 & 9 & 10 & 900 \\
Sünger $(\mathrm{kg})$ & - & 3 & 3 & 5 & 500 \\
Kumaş $\left(m^{2}\right)$ & - & 7 & 8 & 11 & 900 \\
Astar $\left(m^{2}\right)$ & - & 3 & 3.5 & 4 & 450 \\
\hline
\end{tabular}

Ayrıca ürünlerin iskelet parçalarının hazırlanmasından sonra yapılacak olan işlemeler için iş gücü bilgileri Tablo 2'de verilmiştir. 
Tablo 2: İşgücü Kullanım Miktarları

\begin{tabular}{cccccc}
\hline İşücü & $\begin{array}{c}\text { Gümüşlük } \\
\left(x_{1}\right)\end{array}$ & $\begin{array}{c}\text { Tekli Koltuk- } \\
2 \\
\left(x_{2}\right)\end{array}$ & $\begin{array}{c}\text { İkili } \\
\text { Koltuk } \\
\left(x_{3}\right)\end{array}$ & $\begin{array}{c}\text { Üçlü } \\
\text { Koltuk } \\
\left(x_{4}\right)\end{array}$ & Toplam \\
\hline $\begin{array}{c}\text { Parçaların Boyanması } \\
\text { (Dakika) } \\
\begin{array}{c}\text { Parçaların } \\
\text { Verniklenmesi } \\
\text { (Dakika) }\end{array}\end{array}$ & 15 & 17 & 19 & 21 & 1500 \\
$\begin{array}{c}\text { Parçaların } \\
\text { Birleştirilmesi } \\
\text { (Dakika) }\end{array}$ & 9 & 12 & 15 & 17 & 1600 \\
\hline
\end{tabular}

$\mathrm{Bu}$ bilgilerle birlikte işletmenin ürünlerine haftalık gelen talepler sebebiyle sırasıyla; gümüşlük en az 5 adet, tekli koltuk en az 10 adet, ikili koltuk en az 20 adet ve üçlü koltuk en az 40 adet üretilmelidir. İşletme yönetimi bu üretim süreci için üç farklı amaç belirlemiştir. Bunlar;

- $\quad$ Kar Amacı: Ürünler için birim karlar sırası ile; 400 TL., 650 TL, 700 TL. ve 760 TL.' dir (Kar bilgileri işletme yönetimi tarafindan gerçeğe yakın olarak verilmiştir).

- $\quad$ Maliyet Amacı: Ürünler için birim maliyetler sırası ile; 300 TL., 290 TL., 360 TL. ve 440 TL'dir (Maliyet bilgileri işletme yönetimi tarafindan gerçeğe yakın olarak verilmiştir).

- $\quad$ Maksimum birim üretim Amacı: 4 farklı ürünün maksimum miktarda üretilmesi arzu edilmektedir.

$\mathrm{Bu}$ bilgilere işletmenin haftalık üretimi için (9)'a göre Çok Amaçlı Doğrusal Programlama problemi aşağıdaki gibi oluşturulur.

Maksimum $Z_{1}(x)=400 x_{1}+650 x_{2}+700 x_{3}+760 x_{4}$

$\operatorname{Maksimum} Z_{2}(x)=x_{1}+x_{2}+x_{3}+x_{4}$

Minimum $W_{1}(x)=300 x_{1}+290 x_{2}+360 x_{3}+440 x_{4}$

Kisitlar;

$4 x_{1}+7 x_{2}+9 x_{3}+10 x_{4} \leq 900$

$3 x_{2}+3 x_{3}+5 x_{4} \leq 500$

$7 x_{2}+8 x_{3}+11 x_{4} \leq 900$ 
$3 x_{2}+3.5 x_{3}+4 x_{4} \leq 450$

$15 x_{1}+17 x_{2}+19 x_{3}+21 x_{4} \leq 1500$

$9 x_{1}+12 x_{2}+15 x_{3}+17 x_{4} \leq 1600$

$35 x_{1}+42 x_{2}+55 x_{3}+58 x_{4} \leq 4100$

$x_{1} \geq 5$

$x_{2} \geq 10$

$x_{3} \geq 20$

$x_{4} \geq 40$

$x_{1}, x_{2}, x_{3}, x_{4} \geq 0$ ve Tamsay.

Bu modelde;

$x_{1}$ : Üretilecek Gümüşlük adedi,

$x_{2}$ : Üretilecek Tekli Koltuk adedi,

$x_{3}:$ Üretilecek İkili Koltuk adedi,

$x_{4}:$ Üretilecek Üçlü Koltuk adedi.

Uygulama problemi (P1)'in (9)'a göre çözümü sonucunda pozitif ve negatif ideal çözümleri Tablo 3’te verilmiştir.

Tablo 3: (P1) için Pozitif ve Negatif İdeal Çözümler

\begin{tabular}{cccc}
\hline Karar Değişkenleri & $\begin{array}{c}\text { Toplam Kar } \\
Z_{1}(x)\end{array}$ & $\begin{array}{c}\text { Toplam } \\
\text { Üretim } \\
Z_{2}(x)\end{array}$ & $\begin{array}{c}\text { Toplam } \\
\text { Maliyet } \\
W_{1}(x)\end{array}$ \\
\hline$x_{1}$ & 5 & 7 & 5 \\
$x_{2}$ & 12 & 10 & 10 \\
$x_{3}$ & 20 & 20 & 20 \\
$x_{4}$ & 40 & 40 & 40 \\
\hline Amaç Fonksiyonu & & & \\
Değeri & $54200 \mathrm{TL}$ & 77 Adet & $29200 \mathrm{TL}$ \\
(Pozitif İdeal & & & \\
Çözümler) & & 75 Adet & 29800 TL \\
\hline Negatif İdeal Çözümler & $52900 \mathrm{TL}$ &
\end{tabular}


Tablo 3'teki bilgilerden her bir amaç fonksiyonu karar değişkenlerinin farklı değerlerinde gerçekleşmiştir. Bu sonuçlar ise çözümün optimal olmadığını göstermektedir. Tablo 3'teki pozitif ve negatif ideal çözümler kullanılarak düzenlenmiş MA yaklaşımı (12)'ye göre uygulama problemi (P1) için amaçların bulanık hedeflere dönüşümü aşağıda verilmiştir. Kar amacının bulanık hedefe dönüştürülmesi: Kar amaç fonksiyonunun pozitif ideal çözüm değeri 54200TL.' dir. İşletme yönetimi bu değerin altına düşmek istememesine karşın, negatif ideal çözüm yani kar amacının en kötü performans değeri olan 52900 TL. değerini de kabul edilebilir görmüştür.

$$
Z_{1}(x)=400 x_{1}+650 x_{2}+700 x_{3}+760 x_{4} \cong 54200
$$

Bu bilgilere göre kar hedefinin tolerans değeri; $\Delta_{1 L}=54200-52900=1300$ olarak belirlenir. Kar hedefinin üyelik fonksiyonu;

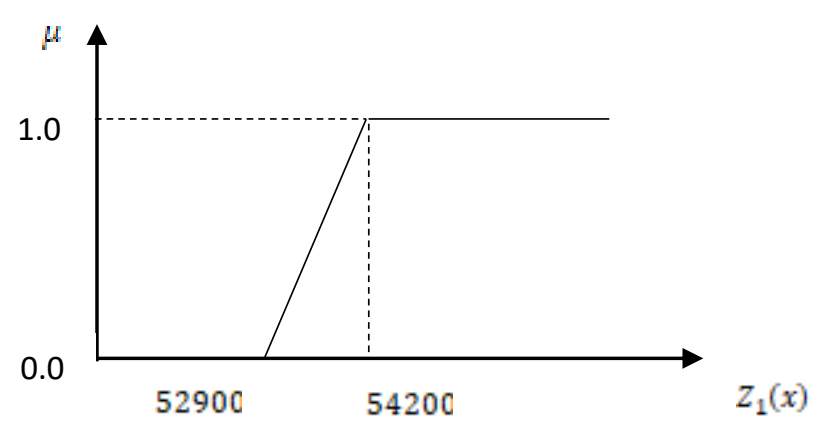

Şekil 4: Bulanık Kar Hedef Üyelik Fonksiyonu

Artan üyelik fonksiyonu matematiksel olarak (6)'ya göre aşağıda verilmiştir.

$\mu_{Z_{1}}(x)=\left\{\begin{array}{ccc}1 & , & Z_{1}(x) \geq 54200 \\ \frac{z_{1}-52900}{1300} & , & 52900 \leq Z_{1}(x) \leq 54200 \\ 0 & , & Z_{1}(x) \leq 52900\end{array}\right.$

Maksimum birim üretim amacının bulanık hedefe dönüştürülmesi: Maksimum birim üretim amacının pozitif ideal çözüm değeri 77 adettir. Bu amacın negatif ideal çözüm değeri de 75 adettir. Buna göre;

$$
Z_{2}(x)=x_{1}+x_{2}+x_{3}+x_{4} \geqq 77
$$

olarak maksimum birim üretim hedefi oluşturulur. $\mathrm{Bu}$ hedef için tolerans değeri $\Delta_{2 L}=77-75=2$ elde edilir. Maksimum birim üretim hedefi içim üyelik fonksiyonu; 


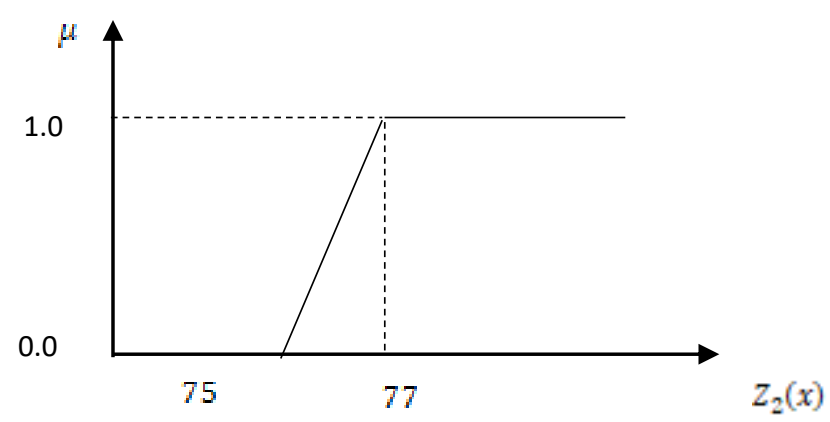

Şekil 5: Bulanık maksimum birim Hedef Üyelik Fonksiyonu

Artan üyelik fonksiyonu matematiksel olarak (6)'ya göre aşağıda verilmiştir.

$\mu_{Z_{2}}(x)=\left\{\begin{array}{ccc}1 & , & Z_{2}(x) \geq 77 \\ \frac{z_{2}-75}{2} & , & 75 \leq Z_{2}(x) \leq 77 \\ 0, & Z_{2}(x) \leq 75\end{array}\right.$

Maliyet amacının bulanık hedefe dönüştürülmesi: Maliyet amacının pozitif ideal çözüm değeri 29200 TL.' dir. Karar verici bu değeri işletme için uygun görmüş olmasına karş1, en kötü performans değeri olan 29800 TL.'yi kabul edebileceğini belirtmiştir. Buna göre bulanık maliyet hedefi

$$
W_{1}(x)=300 x_{1}+290 x_{2}+360 x_{3}+440 x_{4} \widetilde{\Xi} 29200
$$

ve tolerans değeri ise $\Delta_{3 R}=29800-29200=600$ olarak belirlenir. Bu bilgilerden bulanık maliyet hedefi için üyelik fonksiyonu;

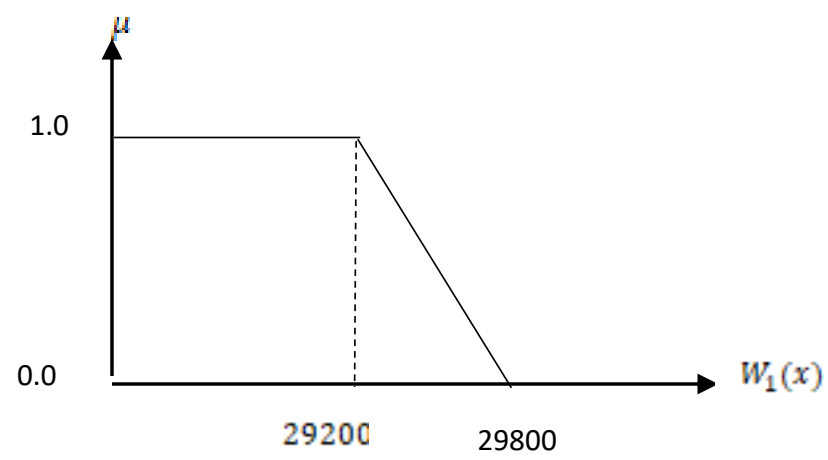

Şekil 6: Bulanık Hedef A için Üyelik Fonksiyonu 
Azalan Üyelik fonksiyonu matematiksel olarak (5)'e göre aşağıda verilmiştir.

$$
\mu_{W_{1}}(x)=\left\{\begin{array}{ccc}
1 & , & W_{1}(x) \leq 29200 \\
\frac{29800-W_{1}(x)}{600} & , & 29200 W_{1}(x) \leq 29800 \\
0 & , & W_{1}(x) \geq 29800
\end{array}\right.
$$

Uygulama problemi (P1), düzenlenmiş MA yaklaşımı (12)'ye göre (13),(14) ve (15) üyelik fonksiyonları kullanılarak aşağıdaki gibi oluşturulur.

Maksimum $\lambda$

Kisitlar;

$$
\begin{aligned}
& 400 x_{1}+650 x_{2}+700 x_{3}+760 x_{4}+n_{1} \geq 54200 \\
& \lambda+\frac{1}{1300} n_{1} \leq 1 \\
& x_{1}+x_{2}+x_{3}+x_{4}+n_{2} \geq 77 \\
& \lambda+\frac{1}{2} n_{2} \leq 1 \\
& 300 x_{1}+290 x_{2}+360 x_{3}+440 x_{4}-p_{3} \leq 29200 \\
& \lambda+\frac{1}{600} p_{3} \leq 1 \\
& 4 x_{1}+7 x_{2}+9 x_{3}+10 x_{4} \leq 900 \\
& 3 x_{2}+3 x_{3}+5 x_{4} \leq 500 \\
& 7 x_{2}+8 x_{3}+11 x_{4} \leq 900 \\
& 3 x_{2}+3.5 x_{3}+4 x_{4} \leq 450 \\
& 15 x_{1}+17 x_{2}+19 x_{3}+21 x_{4} \leq 1500 \\
& 9 x_{1}+12 x_{2}+15 x_{3}+17 x_{4} \leq 1600 \\
& 35 x_{1}+42 x_{2}+55 x_{3}+58 x_{4} \leq 4100 \\
& x_{1} \geq 5
\end{aligned}
$$




$$
\begin{gathered}
x_{2} \geq 10 \\
x_{3} \geq 20 \\
x_{4} \geq 40 \\
x_{1}, x_{2}, x_{3}, x_{4} \geq 0 \text { ve Tamsayi, } \lambda \in[0 ; 1] .
\end{gathered}
$$

Düzenlenmiş MA yaklaşımına göre oluşturulan (P2)'nin çözümünden elde edilen sonuçlar Tablo 4'te verilmiştir.

Tablo 4: (P2)'nin Çözüm Sonucu

\begin{tabular}{cccc}
\hline Karar Değişkenleri & $\begin{array}{c}\text { Toplam Kar } \\
Z_{1}(x)\end{array}$ & $\begin{array}{c}\text { Toplam } \\
\text { Üretim } \\
Z_{2}(x)\end{array}$ & $\begin{array}{c}\text { Toplam } \\
\text { Maliyet } \\
W_{1}(x)\end{array}$ \\
\hline$x_{1}$ & 5 & 5 & 5 \\
$x_{2}$ & 11 & 11 & 11 \\
$x_{3}$ & 20 & 20 & 20 \\
$x_{4}$ & 40 & 40 & 40 \\
\hline Elde Edilen Hedef & $53550 \mathrm{TL}$ & 76 Adet & $29490 \mathrm{TL}$ \\
Değerler & & 0.5 & \\
(P2)'nin Üyelik & & & \\
Derecesi & &
\end{tabular}

Tablo 4'te her bir bulanık hedef aynı karar değişkenlerinin aynı değerinde gerçekleşmiștir. Tablo 4'teki bilgilerden her bir bulanık hedefin kendi ideal çözümüne yakınlık derecesi aşağıda hesaplanmıştır.

Bulanık Kar Hedefi: $\frac{53550-52900}{1300}=0.5$

Bulanık Birim üretim Hedefi $\frac{76-75}{2}=0.5$

Bulanık Maliyet Hedefi: $\frac{29800-(29490)}{600}=0.5$

Bulanık Hedeflerin kendi ideal çözümlerine yakınlık dereceleri ile (P2)'nin üyelik derecesi 0.5 olarak belirlenmiştir. Bu sonuç ise (P2)'nin çözümünün etkin bir çözüm olduğunu gösterir. Diğer yandan, kar hedefinden sapma miktarı $n_{1}=650 \mathrm{TL}$, maksimum birim hedefinden sapma miktarı $n_{2}=1$ adet ve maliyet hedefinden sapma ise $p_{3}=310$ TL olarak 
belirlenmiştir. (P2)'nin çözümünden belirlenen çözüme “bulanık tatminkâr çözüm” adı verilebilir

\section{SONUÇ}

Hedef Programlama açısından kurulan modellerde sadece hedef fonksiyonuna göre çözüm yapılabildiği gibi, hedef fonksiyonlarının kısıtlara bağlı olarak değerlendirilmesi mümkündür. Hedef Programlama yönteminde karar vericiler hedeflerinin arzu edilen seviyelerini kendileri belirlediği takdirde bazı hedef ve/veya hedeflerden sapmalar çok fazla olabilir. Diğer yandan hedeflere verilecek olan öncelik sıralaması veya göreceli ağırlıklar farklı sonuçlara da yol açacak ve sapmaların artmasına sebep olacaktır. Bu beklenilen bir durum olup, sapmaların yanlış yorumlanmasına neden olabilir. Ayrıca hedeflerin arzu edilen seviyelerinin bulanıklaştırılması da sapmaların artmasını sağlayabilir. Özellikle problemde, hedef fonksiyonlarından başka ilgili sistemin kısıtları varsa çözüm, kısıtların sağladığı bölge üzerinde gerçekleşeceği için saplamalar çok daha fazla artabilir.

İşletmeyle yapılan ilk görüşmelerde, yönetici mevcut üretiminin sadece kar amaçlı olduğunu ve üretim sistemini buna bağlı olarak geliştirdiğini belirtmiştir. İşletme yönetimine kar amacının yanı sıra maksimum birim üretim ile minimum maliyet amacı oluşturularak üretim sürecinin üç amaca bağlı yapılması önerilmiş ve bu öneri kabul edilmiştir. Üretim sisteminin modellenen problemi her üç amaç için ayrı ayrı çözüm yapılmış ve çözüm sonucunda amaçların farklı değişken değerlerinde gerçekleştiği belirlenmiştir. Tablo 3'teki bilgilerden; her üç amaç fonksiyonu için 20 adet ikili koltuk ile 40 adet üçlü koltuk üretimi belirlenirken, bu üç amaç fonksiyonu için gümüşlük ve tekli koltuk-2'nin farklı miktarlar elde edilmiştir. Bu çözüm sonucu ise beklenilen bir durumdur. Çünkü Çok Amaçlı Doğrusal Programlama problemlerinde bütün amaçların aynı karar değişekelerinin aynı değerinde gerçekleşmesi hemen hemen imkânsızdır. $\mathrm{Bu}$ nedenle her üç amacı aynı karar değişkenlerinin aynı değerinde gerçekleştirmek için Çok Amaçlı Karar Verme yöntemlerinden olan Hedef Programlanın bir uzantısı olan Bulanık Hedef programlama kullanılmıştır. Bulanık Hedef Programlamanın temeli olan Narasimhan (1980) ve Hannan (1981) tarafindan geliştirilen yaklaşımlarda hedef fonksiyonlar için bulanık hedefler ile bu hedeflerin tolerans değerleri karar verici tarafından belirlenmektedir. Bu yaklaşımlarda, hedef fonksiyonlar için tanımlanan hedef değerler ile bunların tolerans değerlerindeki olabilecek yanlışlıklar tüm problemin yanlış sonuç vermesine ve yorumlanmasına sebep olacaktır. Oluşabilecek bu tip yanlışlıkları önlemek için MA (2007) yaklaşımı tercih edilmiştir. Çünkü MA yaklaşımı pozitif ve negatif ideal çözümleri kullanmak için çok uygun bir yöntemdir. 
$\mathrm{Bu}$ çalışmada Çok Amaçlı Doğrusal Programlama problemi olarak düzenlenen uygulama problemi (P1)'in her bir amaç fonksiyonu bulanık hedef fonksiyonlarına dönüştürülürken, bu amaçların pozitif ideal çözümleri kullanılmıştır. Çünkü (P1)'deki amaçların ulaşabilecekleri en iyi değerler kendi pozitif ideal çözümleridir. Negatif ideal çözüm değerleri ise en kötü performansları olup, pozitif ve negatif ideal çözümler arasındaki fark ise bulanık hedef fonksiyonlar için tolerans değerleri olarak kabul edilmiştir. Birinci amaç fonksiyonu gözönünde buludurulduğunda pozitif ideal çözüm 54200 TL ve negatif ideal çözüm 52900 TL'dir. Bu bilgiler kullanılarak oluşturulan Şekil 4 ve üyelik fonksiyonu (13)'e göre kar amacı bulanık hedefe dönüştürülmüştür. Maksimum birim üretim amacı için bulanık hedefe dönüştürme sürecinde Şekil 5 ve üyelik fonksiyonu (14), maliyet amacı için ise Şekil 6 ve üyelik fonksiyonu (15) kullanılmıştır. Bulanık Hedef Programlamaya göre yapılan çözüm sonucunda; her üç hedef aynı değişkenlerin/aynı ürünlerin miktarına bağlı ortaya çıkmıştır. Bu miktarlar gümüşlük için 5 adet, tekli koltuk-2 için 11 adet, ikili koultuk için 20 adet ve üçlü koltuk için 40 adettir. Bu bilgiler kullanılarak bulanık hedefler; Kar amacı için 53550 TL, birim üretim amacı 76 adet ve maliyet amacı ise 29490 TL olarak belirlenmiştir. (P2)'nin çözümüne ait tüm sonuçlar Tablo 4'te görülebilir.

Kar hedefi için; Hedefe dönüştürülen kar amacının pozitif ideal çözümü 54200 TL ve negatif ideal çözümü ise 52900 TL'dir. Bu hedef için tolerans değeri pozitif ve negatif ideal çözümlerin farkından 1300 TL olarak elde edilir. (P2)'nin çözümü sonucunda Kar hedefinin bulanık tatminkâr değeri 53550 TL olarak belirlenmiştir ki bu değer belirlenen aralık içerisinde gerçekleşmiştir. Diğer hedefler içinde benzer hesaplama yapılarak, her bir hedefin belirlenen aralıklar içerisinde kaldığı belirlenebilir. Sonuç olarak, bu uygulama çalışmasında kullanılan MA yaklaşımıyla, Çok Amaçlı Doğrusal Programlama problemlerinin pozitif ve negatif ideal çözüm kavramlarına bağlı olarak çözülebileceği bir gerçek işletme problemi üzerinde gösterilmiştir. 


\section{KAYNAKÇA}

Bellman,R.E., and Zadeh,L.A. (1970). “Decision-Making in A Fuzzy Environment”, Management Science B.17, pp. 141-164.

Charnes, A., and Cooper, W. W. and Ferguson, R. (1955). "Optimal estimation of executive compensation by linear programming”, Management Science, vol. 1, no. 2, pp. 138-151.

Charnes, A., and Cooper, W.W. 1961, Management Models and Industrial Applications of Linear Programming, Wiley, New York.

Charnes, A., and Cooper, W.W. (1977). "Goal programming and multiple objective optimizations”, Eur. J. Oper. Res., vol. 1, issue 1, pp. 39-54.

Chen, L-H., Ko, W-C., and Yeh,F-T. (2017). “Approach based on fuzzy goal programing and quality function deployment for new product planning”, European Journal of Operational Research,259 pp. 654-663

Chen, L. H., and Tsai, F.C. (2001). "Fuzzy goal programming with different importance and priorities", European Journal of Operational Research, 133, 548-556.

Cheng, H.W. (2013). “A satisficing method for fuzzy goal programming problems with different importance and priorities”, Qual. Quant, 47,485-498.

Silva, A.F., and Marins,F.A.S.(2014). "A Fuzzy Goal Programming model for solving aggregate productionplanning problems under uncertainty: A case study in a Brazilian sugar mill, Energy Economics 45, pp.196-204.

Erpolat, S. (2010). "Üretim Planlamasında Hedef Programlama ve Bulanık Hedef Programlama Yöntemlerinin Karşılaştırılması”, Öneri, C.9.S.34. Temmuz, pp.233-246.

Flavell, R.B. (1976). “A new goal programming formulation”, Omega, vol. 4, no. 6, 731-732, 1976.

Gupta, M., and Bhattacharjee, D. (2012). “Two weighted fuzzy goal programming methods to solve multiobjective goal programming problem”, Journal of applied mathematics, volume 2012,1-20.

Hannan, E. L. (1981), “On fuzzy goal programming”, Decision Sciences, 12, 522-531.

Ijiri,Y. (1965). Management Goals and Accounting for Control, Amsterdam, North-Holland Publishing Co.

Jones, D., and Tamiz, M. (2010). Practical goal programming, International Series in Operations Research and Management Science, 141 (141). Springer, New York.

Lee, S.E., and Moore, L.J. (1975). Introduction to Decision Science, Petrocelli- Charter, New York.

Liang, T-F. (2007). “Applying fuzzy goal programming to production/transportation planning decisions in a supply chain”, International Journal of Systems Science Vol. 38, No. 4, pp.293-304.

Lin, C.C. (2004). “A weighted max-min model for fuzzy goal programming”, Fuzzy Sets and Systems 142, 407420.

Lutero, D.S., Pangue,E.M.U, Tubay,J.M., and Lubag, S.P. (2016). “A fuzzy goal programming model for biodiesel production”, Journal of Physics: Conference Series 693 (2016) 012007, doi:10.1088/17426596/693/1/012007

Min, H., and Storbeck,J. (1991). "On the Origin and Persistence of Misconceptions in Goal Programming”, Journal of the Operational Research Society, Vol. 42, pp.301-312.

Mokhtaria, H. and Hasani, A. (2017).’Multi-objective model for cleaner production-transportationplanning in manufacturing plants via fuzzy goal programming", Journal of Manufacturing Systems 44, pp.230-242.

Romero, C. (1991). Handbook of Critical Issues in Goal Programming, Perganom Press, New York .

Narasimhan, R. (1980). “Goal programming in a fuzzy environment”, Decision Sciences, 11, 325-336.

Özkan, M. ve Bircan, H.(2016). “Bulanık Hedef Programlama ile Ürün Hedef Optimizasyonu: Yang, Ignizio ve Kim Modeli”, İstanbul Üniversitesi İşletme Fakültesi Dergisi, Vol/Cilt: 45, No/Sayı:2, November/Kasım, pp.109-119.

Rubin, P.A., and Narasimhan, R. (1984). Fuzzy goal programming with nested priorities. Fuzzy sets and systems $14,115-129$. 
Schniederjans, M.J. (1994). Goal Programming: Methodology And Applications, Kluwer Academic Publishers, Boston.

Simon, H.A. (1960). The New Science of Management Decision, Harper \& Brothers Publishers, First Edition, New York.

Tsai, K-M., HsinLin, S-Y.Y., and Tsai, C-H. (2008). "A fuzzy goal programming approach with priority for channel allocation problem in steel industry”, Expert Systems with Applications, Volume 34, Issue 3, pp. 1870-1876.

Tiwari, R.N., Dharmar, S. \& Rao, J.R. (1986). Priority structure in fuzzy goal programming. Fuzzy sets and systems 19, 251-259.

Zadeh, L.A. (1965). "Fuzzy Sets", Information and Control 8,s. 338-353.

Zeleny, M.(1982). Multiple Criteria Decision Making, McGraw-Hill Book Company, New York.

Zimmerman, H.J. (1978). Fuzzy programming and linear programming with several objective functions, Fuzzy sets and systems 1 (1978) 45-55.

Yaghoobi, M.A., and Tamiz, M. (2007). “A method for solving fuzzy goal programming problems based on minmax approach”, European Journal of Operational Research 177, 1580-1590.

Yang, T., Ignizio, J. P., and Kim, H. J. (1991). "Fuzzy programming with nonlinear membership functions: piecewise linear approximation", Fuzzy Sets and Systems, 41, 39-53. 